\title{
Truncated WT1 Protein Isoform Expression Is Increased in MCF-7 Cells with Long-Term Estrogen Depletion
}

\author{
Saavedra-Alonso Santiago (D), Zapata-Benavides Pablo, Mendoza-Gamboa Edgar, \\ Chavez-Escamilla Ana Karina, Arellano-Rodríguez Mariela, and Rodriguez-Padilla Cristina
}

\author{
Department of Immunology and Virology, Faculty of Biological Sciences, Autonomous University of Nuevo Leon (UANL), \\ San Nicolas de los Garza, Nuevo Leon 66450, Mexico \\ Correspondence should be addressed to Saavedra-Alonso Santiago; ssaavedraln@uanl.edu.mx
}

Received 12 May 2020; Revised 26 May 2021; Accepted 27 September 2021; Published 20 November 2021

Academic Editor: Pranshu Sahgal

Copyright (c) 2021 Saavedra-Alonso Santiago et al. This is an open access article distributed under the Creative Commons Attribution License, which permits unrestricted use, distribution, and reproduction in any medium, provided the original work is properly cited.

\begin{abstract}
Background. The $w t 1$ gene codes for a transcription factor that presents several protein isoforms with diverse biological properties, capable of positively and negatively regulating genes involved in proliferation, differentiation, and apoptosis. WT1 protein is overexpressed in more than $90 \%$ of breast cancer; however, its role during tumor progression is still unknown. Methodology. In this work, we analyzed the expression of WT1 isoforms in several breast cancer cells with different tumor marker statuses and an in vitro assay using MCF-7 cells cultured with long-term estrogen depletion (MCF-7 LTED cells) with the finality to mimic the process of switching from hormone-dependent to hormone-independent. Moreover, growth kinetics, sensitivity to tamoxifen, and relative expression analysis of ER and Her2/neu were performed. Results. Initially, the expression of $52-54 \mathrm{kDa}$ protein isoform of WT1 in the breast cancer cell line ER (+) was detected by western blot and was absent in ER (-), and the $36-38 \mathrm{kDa}$ protein isoform of WT1 was detected in all cell lines analyzed. The analysis of alternative splicing by RT-PCR shows that the 17AA (+)/KTS (-) isoform of WT1 was the most frequent in the four cell lines analyzed. In vitro, the MCF-7 cells in the estrogen depletion assay show an increase in the expression of the $52-54 \mathrm{kDa}$ isoform of WT1 in the first 48 hours, and this was maintained until week 13 , and later, this expression was decreased, and the $36-38 \mathrm{kDa}$ isoform of WT1 did not show change during the first 48 hours but from week 1 showed an increase of expression, and this remained until week 27. Growth kinetic analysis showed that MCF-7 LTED cells presented a 1.4-fold decrease in cellular proliferation compared to MCF-7 cells cultured under normal conditions. In addition, MCF-7 LTED cells showed a decrease in sensitivity to the antiproliferative effect of tamoxifen $(p \leq 0.05)$. Samples collected until week 57 analyzed by qRT-PCR showed an increase in the relative expression of the Her2/neu and ER. Conclusions. Modulation of protein isoforms showed differential expression of WT1 isoforms dependent on estrogen receptor. The absence of $52-54 \mathrm{kDa}$ and the presence of the $36-38 \mathrm{kDa}$ protein isoform of WT1 were detected in ER-negative breast cancer cell lines classified as advanced stage cells. Long-term estrogen depletion assay in MCF-7 cells increased the expression of the $36-38 \mathrm{kDa}$ isoform and reduced the $52-54 \mathrm{kDa}$ isoform, and these cells show an increase in the expression of tumor markers of ER and Her2/neu. MCF-7 LTED cells showed low proliferation and insensitivity to tamoxifen compared to MCF-7 cells in normal conditions. These results support the theory about the relationship of the $36-38 \mathrm{kDa}$ isoform of $\mathrm{WT} 1$ and the absence of ER function in advanced breast cancer.
\end{abstract}

\section{Introduction}

Wilms' tumor gene (wt1) consists of 10 exons that encode a zinc finger transcription factor involved in genitourinary development during embryogenesis $[1,2]$. Recent studies have described the WT1 protein as an oncogene because, in cancer, it regulates genes responsible for cell growth, apoptosis, and tumoral angiogenesis such as cyclin D1, Bcl-2, Bcl-xL, BFL1, c-myc, and VEGF [3-8]. The WT1 protein contains an $\mathrm{N}$-terminal protein region with a 
domain involved in transcriptional regulation, self-association, and RNA recognition [9-11] and a C-terminal protein region that contains a DNA/RNA binding domain and four zinc finger domains that can bind to GC-rich sequences [12-14].

The wt1 gene has two alternative splicing sites, identified as exon 5 or 17AA and another that occurs in exon 9, identified as KTS (Lys-Thr-Ser) [15]. The different isoforms are referred to as (A) the isoform that lacks both the 17 amino acid and KTS inserts, (B) the isoform that contains the 17 amino acid inserts but lacks the KTS insert, (C) the isoform that lacks the 17 amino acid inserts but contains the KTS insert, and (D) the isoform that contains both inserts [16, 17]. Moreover, WTI has three sites of initiation of translation that produce three isoforms of different molecular weights $(62-64 \mathrm{kDa}, 52-54 \mathrm{kDa}$, and $36-38 \mathrm{kDa})$ with different biological properties [18, 19]. The $62-64 \mathrm{kDa}$ WT1 protein isoform is not essential for normal development and reproduction in mice [20], while the $36-38 \mathrm{kDa} \mathrm{WT} 1$ protein isoform has more oncogenic potential than the WT1 $52-54 \mathrm{kDa}$ protein isoform in leukemia cells $[20,21]$.

It has been reported that WT1 appears to have a growth regulatory role in many solid cancers including lung [22], colon [23], pancreatic [24], breast [25], and gastric [26], as well as in leukemia [27] and lymphoma [28]. In breast cancer, Silberstein et al. initially considered WT1 to be a tumor suppressor gene, because its overexpression was found in healthy tissue and not in breast cancer tissue [29]; however, subsequent work by Loeb et al. reported that WT1 expression is found in $90 \%$ of breast cancer samples [25]. Miyoshi et al. correlated high levels of wt1 mRNA with a poor prognosis and survival rate in breast cancer patients [30], and Oji et al. demonstrated that the wildtype $w t 1$ gene plays an important role in the tumorigenesis of breast cancer [31].

Currently, it is not fully known how WT1 interacts with tumor markers used in the characterization of breast cancer, such as the estrogen receptor, progesterone receptor, and Her2/neu. Studies in breast cancer lines have demonstrated that WT1 expression is involved in the modulation of tumor marker expression. Zapata-Benavides et al. found that WT1 protein was decreased by around $60 \%$ in MCF-7 cells cultured without estrogen, but WT1 expression was restored after $17 \beta$-estradiol treatment [32]. Another work related to tumor markers in breast cancer was performed by Tuna et al., where it was observed that the signaling pathway of Her2/neu through Akt regulated levels of WT1 expression, concluding that WT1 protein plays a vital role in the regulation of cell cycle progression and apoptosis [33]. Accordingly, based on these previous studies, we hypothesize that overexpression of $w t 1$ and a change in isoform allow WT1 to be present at different stages of breast cancer progression.

In this study, we analyzed the expression of WT1 isoforms, ER, and Her2/neu in a long-term estrogen depletion in vitro model, to mimic the malignant progression of the breast cancer switch from estrogen-dependent to estrogenindependent growth.

\section{Methodology}

2.1. Cell Culture. In the initial assays, MCF-7, BT-474, T47D, SKBR-3, MDA-MB-231, MDA-MB-453, and BT-20 breast cancer cells were obtained from ATCC (American Type Culture Collection, Manassas, VA). All cell lines were grown in DMEM/F12 (Invitrogen, USA) medium supplemented with $10 \%$ fetal bovine serum (FBS, Invitrogen, USA) and incubated in $95 \%$ air with $5 \% \mathrm{CO}_{2}$ at $37^{\circ} \mathrm{C}$.

2.2. Quantitative RT-PCR. The total RNA of tissue was isolated using $1 \mathrm{~mL}$ of reagent TRIzol (Life Technologies, Gaithersburg, MD) according to the manufacturer's instructions. The DNAc was performed using $5 \mu \mathrm{g}$ of total RNA, Superscript II, and oligo $\left(\mathrm{dT}_{12-18}\right)$ under the condition at $42^{\circ} \mathrm{C}$ for $90 \mathrm{~min}$, followed by heating at $70^{\circ} \mathrm{C}$ for 10 minutes. Each reaction of PCR real-time was made using $2 \mu \mathrm{L}$ of DNAc. To Her $2 /$ neu was used forward primer $5^{\prime}$-GAGGCACCCAG CTCTTTGA-3' ${ }^{\prime}$, reverse primer $5^{\prime}$-CGGGTCTCCATTGTCT AGCA- $3^{\prime}$, and probe Fam-5 '-CCAGGGCATAGTTGTCC$3^{\prime} \mathrm{NFQ}$, and to ER was used forward primer CGACATGCT GCTGGCTACA, reverse primer $5^{\prime}$-ACTCCTCTCCCTGC AGATTCAT- $3^{\prime}$, and probe Fam- $5^{\prime}$-CATGCGGAACCGAG ATGA- $3^{\prime}$ NFQ. The human $\beta$-actin primer set manufactured by Applied Biosystems was used as the endogenous control. For each reaction, Universal PCR Master Mix was used (Roche Branchburg, New Jersey, USA). The protocol was performed for 40 cycles at $94^{\circ} \mathrm{C}$ for 30 seconds and $64^{\circ} \mathrm{C}$ for 30 seconds. The calculation of relative expression was conducted using the Livak method [34].

2.3. PCR to Detect Spliced Isoforms of $17 A A / K T S$. Ratios of isoform spliced of $w t 1$ gene, 17AA (-)/KTS (-), 17AA $(-) / \operatorname{KTS}(+), 17 \mathrm{AA}(+) / \mathrm{KTS}(-)$, and 17AA $(+) / \mathrm{KTS}(+)$ to total wt 1 transcripts were obtained by PCR according to Oji et al. [22]. The primer sequences were as follows: F2 $5^{\prime}$ -GACCTGGAATCAGATGAACTTAG-3 and R2 5-GAGA ACTTTCGCTGACAAGTT- $3^{\prime}$ to determine the ratio of 17AA $(+) /(-)$ and F3 $5^{\prime}$-GTGTGAAACCATTCCAGTG TA- $3^{\prime}$ and R3 $5^{\prime}$-TTCTGACAACTTGGCCACCG-3' to determine the ratio of KTS $(+) /(-)$. PCR amplification was performed with 35 cycles at denaturalization $94^{\circ} \mathrm{C}$ for $60 \mathrm{sec}$, alignment at $56^{\circ} \mathrm{C}$ for $60 \mathrm{sec}$, and extension of $72^{\circ} \mathrm{C}$ for $90 \mathrm{sec}$. All PCR products were analyzed on $10 \%$ acrylamide gels and visualized with ethidium bromide under UV light.

2.4. Western Blot to Detect WT1 Protein Isoforms. Total protein collection was performed using reagent TRIzol according to the manufacturer's instructions. Protein samples $(50 \mu \mathrm{g})$ were electrophoresed on 12\% SDS-polyacrylamide gels and transferred to nitrocellulose membranes. Immunodetection of WT1 protein isoform was performed using a WT1C19 polyclonal antibody (COOH-terminal binding, Santa Cruz Biotechnology); the $\beta$-actin monoclonal antibody was obtained from Sigma Chemical (St Louis, MO), and anti-mouse and anti-rabbit antibodies conjugated with horseradish peroxidase were purchased from Bio-Rad. 
Protein bands were visualized by enhanced chemiluminescence using Roche Lumi-Light Western blotting substrate. Subsequently, the bands obtained were analyzed by densitometry using the ImageJ program (https://imagej.nih.gov/ ij/download.html). The density of each band was normalized with its respective value of $\beta$-actin.

2.5. Long-Term Estrogen Depletion Assay. MCF-7 cells were grown in DMEM/F12 culture medium supplemented with $10 \%$ FBS until $60 \%$ confluence. Thereafter, the cells were washed twice with sterile buffer PBS to eliminate the phenol red, and the culture medium was replaced with DMEM/F12 phenol red-free supplemented with $10 \%$ charcoal-dextrantreated FBS manufactured by HyClone (Road Logan Utah, USA). The sample was made until reaching $80 \%$ of the confluence of cell growth in the flask.

2.6. Growth Kinetics. Cell growth was assessed after seeding $2.5 \times 10^{5} \mathrm{MCF}-7$ cells under normal conditions and MCF7 LTED cells (27 weeks) per well in six-well plates using the respective culture medium. Cells were harvested at 24 and 72 hours and quantified by trypan blue exclusion staining. Each count was done in triplicate and normalized to the initial number of cells.

2.7. Assays of MCF-7 LTED Cells Treated with Tamoxifen. MCF-7 cells under normal conditions and MCF-7 LTED cells ( 27 weeks) were seeded $\left(3 \times 10^{3}\right.$ per well) in a 96-well plate. After 24 hours of incubation, tamoxifen was added at $1.25 \mu \mathrm{M}, 2.5 \mu \mathrm{M}, 5 \mu \mathrm{M}$, and $10 \mu \mathrm{M}$. Each treatment was carried out in triplicate including control untreated cells. The plates were then incubated for 24 hours, then were analyzed using the MTT assay. The MTT reagent (3-(4,5dimethylthiazol-2-yl)-2,5-diphenyl tetrazolium bromide) was purchased from Sigma-Aldrich. MTT solution was prepared at $5 \mu \mathrm{g} / \mathrm{mL}$ in PBS buffer; then, $20 \mu \mathrm{L}$ of the MTT solution was added per well, and then, the plate was incubated at $37^{\circ} \mathrm{C}$ for 1 hour. Finally, the medium was removed, and $200 \mu \mathrm{L}$ of DMSO was added to solubilize the formazan salt. The plate was analyzed using a microplate reader (Microplate Autoreader EL311, BioTek Instruments Inc., Winooski, Virginia, USA) at $570 \mathrm{~nm}$ to determine the optical density (OD).

2.8. Statistical Analysis. The significance of different treatments was determined by analysis of variance and Student's $t$-test. Differences were considered significant at $p \leq 0.05$ using SPSS software, version 13 (SPSS, Inc., Chicago, IL, USA). All data are expressed as the mean \pm the standard error. $p<0.05$ was considered to indicate a statistically significant difference. To calculate $\mathrm{IC}_{50}$, AAT Bioquest, Inc. (2019, September 02) was used, Quest Graph ${ }^{\mathrm{TM}} \mathrm{IC}_{50}$ Calculator (https://www.aatbio.com/tools/ic50-calculator).

\section{Results}

3.1. WT1 Protein Isoform Expression in Breast Cancer Cell Lines. Initially, the characterization of the expression of the WT1 isoforms was carried out in the breast cancer cell lines MCF-7, BT-474, T47D, SKBR-3, MDA-MB-231, MDA-MB-
TABLE 1: Tumor marker status of breast cancer cell lines.

\begin{tabular}{lccc}
\hline Cell line & $\begin{array}{c}\text { Estrogen } \\
\text { receptor }\end{array}$ & $\begin{array}{c}\text { Tumor markers } \\
\text { Progesterone } \\
\text { receptor }\end{array}$ & $\begin{array}{c}\text { Her2/ } \\
\text { neu }\end{array}$ \\
\hline MCF-7 & + & - & - \\
BT-474 & + & + & + \\
T47D & + & + & - \\
SKBR-3 & - & - & + \\
MDA-MB-231 & - & - & - \\
MDA-MB-453 & - & - & Low \\
BT-20 & - & - & - \\
\hline
\end{tabular}

Present (+); absent (-); Her2/neu: human epidermal growth receptor 2 . Adapted from [36, 37].

453, and BT-20. WT1 protein expression was detected in all these cell lines, with different isoform patterns. The 52$54 \mathrm{kDa}$ WT1 isoform was expressed only in the estrogen receptor-positive (MCF-7, BT-474, and T47D) but was not expressed in the estrogen receptor-negative cell lines (tumor marker status is shown in Table 1) SKBR-3, MDA-MB-231, MDA-MB-453, and BT-20 (Figure 1(a)). Moreover, the 36$38 \mathrm{kDa}$ WT1 isoform was expressed in all breast cancer cells. To assess 17AA/KTS alternative splicing, four of the seven cell lines were analyzed by conventional RT-PCR. MCF-7 cells expressed four isoforms, and BT-474, SKBR-3, and MDA-MB-231 cells only expressed the 17AA +/KTS - isoform (Figure 1(b)).

3.2. MCF-7 Cells in Short-Term Estrogen Depletion Increase the Expression of $52-54 \mathrm{kDa}$ WT1 Protein Isoform. To analyze the effects of estrogen depletion on WT1 expression, several assays were carried out in MCF-7 estrogen receptor-positive cells. MCF-7 cells cultured under normal conditions were changed to medium under conditions of estrogen depletion for 24 and 48 hours; then, western blotting was performed. The expression of the WT1 protein isoform of $36-38 \mathrm{kDa}$ was not affected considerably; this expression showed an increase of $22 \%$ and $25 \%$ at 24 and 48 hours, respectively, but the expression of the WT1 protein isoform of $52-54 \mathrm{kDa}$ showed a considerable increase of $108 \%$ and $131 \%$ at 24 and 48 hours, respectively (Figures 2(a) and 2(c)).

3.3. MCF-7 Cells in Long-Term Estrogen Depletion Decrease Their Expression of the $52-54 \mathrm{kDa}$ and Increase the 36$38 \mathrm{kDa}$ WT1 Protein Isoforms. Subsequently, samples of MCF-7 cells were collected over a period of several weeks of long-term estrogen depletion (MCF-7 LTED cells) and were analyzed to determine the expression of WT1 isoforms by western blot. The expression of the $52-54 \mathrm{kDa}$ WT1 protein isoform showed a slight decrease concerning the first week, and this was present until week 13 with a value of $92 \%$; later, the expression decreases from week 18, and it remains low with 3 and 5\% in weeks 22 and 27, respectively; however, the expression of the WT1 protein isoform of 36$38 \mathrm{kDa}$ decreases at week 5 to $57 \%$, and it remains present 


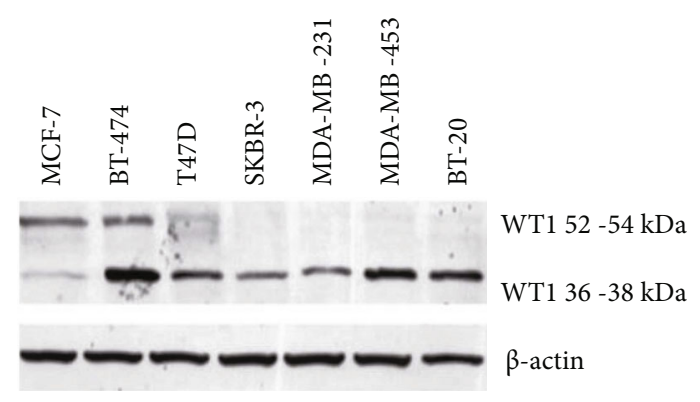

(a)

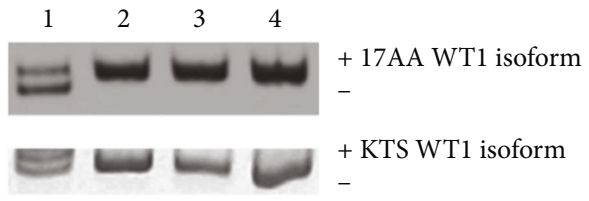

(b)

FIgURE 1: Expression of WT1 isoforms in breast cancer cell lines. (a) The $52-54 \mathrm{kDa}$ and $36-38 \mathrm{kDa}$ WT1 isoforms were analyzed in breast cancer cell lines. The expression of $\beta$-actin was included as the endogenous control. (b) Analysis of alternative splicing 17AA/KTS in breast cancer cell lines (lane 1: MCF-7; lane 2: BT474; lane 3: SKBR-3; lane 4: MDA-MB-231).

between $44 \%$ and $101 \%$ in all samples collected during the rest of the weeks analyzed (Figures $2(\mathrm{~b})$ and $2(\mathrm{~d})$ ).

\subsection{The Low Proliferation Rate of MCF-7 Cells Cultured with} Long-Term Estrogen Depletion. Growth kinetic assays were performed to compare MCF-7 cells cultured in medium under normal conditions against MCF-7 LTED cells cultured for 27 weeks in culture medium with estrogen depletion. The assay was performed using the culture medium corresponding to each of the estrogen conditions. MCF-7 LTED cellular proliferation was significantly decreased by 1.4 -fold $(p \leq 0.05)$ in comparison with MCF-7 cells cultivated under normal conditions (Figure 3(a)).

3.5. Effect of Tamoxifen on MCF-7 LTED Cells. Subsequently, a tamoxifen sensitivity test was performed on MCF-7 LTED cells (27 weeks) compared to MCF-7 cells cultured under normal conditions. MCF-7 LTED cells were less sensitive $\left(\mathrm{IC}_{50}=4.935 \mathrm{mM}\right)$ to the inhibitory effects of tamoxifen in comparison to MCF-7 cells cultured under normal conditions $\left(\mathrm{IC}_{50}=3.278 \mathrm{mM} ; p \leq 0.05\right.$ ) (Figure 3(b)). MCF-7 LTED cells were much less sensitive to the antiproliferative effect of tamoxifen.

3.6. Analysis of Her2/neu and Estrogen Receptor Expression in MCF-7 LTED Cells. To observe the behavior of the molecular markers Her2/neu and ER, a quantitative RT-PCR analysis was performed using MCF-7 LTED cells collected at several time points. The mRNA expression of Her2/neu and ER was significantly increased in MCF-7 LTED cells, starting from week 22 until week 53, with an increase of 2.98 -fold ( $\mathrm{SD} \pm 0.43$ ) and 2.59 -fold $(\mathrm{SD} \pm 0.99)$ in the expression of Her2/neu (Figure 4(a)) and ER (Figure 4(b)), respectively.

\section{Discussion}

Breast cancer represents a major health problem worldwide, due to its high incidence and high mortality; it is the second leading cause of cancer death in general and the leading cause of cancer death in women [35]. The molecular classification of breast cancer is performed using the tumor markers progesterone receptor, ER, and Her2/neu. ER and Her2/neu are the most important tumor markers in breast cancer because their presence dictates the type of therapy to be followed and the prognosis of the disease [36, 37]. A critical step in the malignant progression of breast cancer is the switch from estrogen-dependent to estrogenindependent growth [38]. During this change in hormonal dependence, the activity of Her2/neu is increased, leading to a high metastatic potential [39].

High expression of wild-type WT1 in breast cancer has been reported in more than $90 \%[25,30]$, and high levels of WT1 expression have been inversely associated with patient survival. The presence of WT1 is essential for breast cancer cell growth [32]; however, it is still unclear what role it plays during the progression of breast cancer. WT1 can act as a tumor suppressor gene or as an oncogene, possibly due to the presence of various isoforms that have different biological properties [40].

According to the two splicing alternatives, the four isoforms are expressed in several solid cancers, including lung cancer [30], HNSCC [41] sarcoma [42], breast cancer [43], and human primary leukemia [44]. However, the functions of each of the four WT1 isoforms in cancer cells remain unclear [45]. In the present study, we analyzed the WT1 isoforms present in breast cancer cell lines. The presence of the $52-54 \mathrm{kDa}$ WT1 isoform was observed in ER-positive cell lines and not detected in ER-negative cell lines. The 36$38 \mathrm{kDa}$ WT1 isoform was present in all the cell lines analyzed. The biological function of the $36-38 \mathrm{kDa}$ WT1 isoform is not clear yet. The $36-38 \mathrm{kDa}$ WT1 isoform lacks the first 128 amino acids of the N-terminal region, which generates loss of the dimerization domain and a loss of the repression domain. Its presence has been determined in cell lines and specimens of Wilms' tumor where it has been reported that its transactivating function is 1.5 -fold higher than the $52-54 \mathrm{kDa}$ WT1 isoform KTS (-). The $36-38 \mathrm{kDa}$ isoform of WT1 may be involved in the progression of the neoplasm due to the lack of the repression domain [19].

To assess the alternative splicing of $w t 1$, we observed that MCF-7 cells presented the four isoforms (17AA (+/-)/KTS $(+/-))$ and the other cell lines only expressed the 17AA $(+) /$ KTS (-)wt1 isoform. This result agrees with the results reported by Nasomyon et al. where they find that MCF-7 cells express the 4 possible isoforms according to both alternative splicings in WT1 [46]. The 17AA (+) wt1 isoforms are 


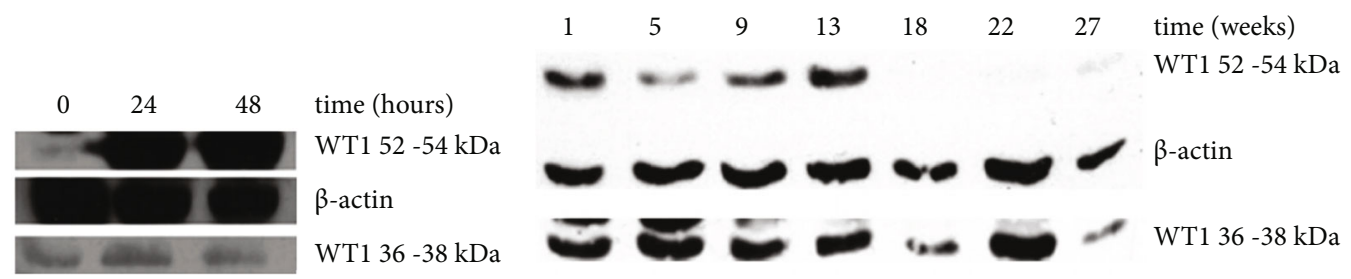

(a)

(b)

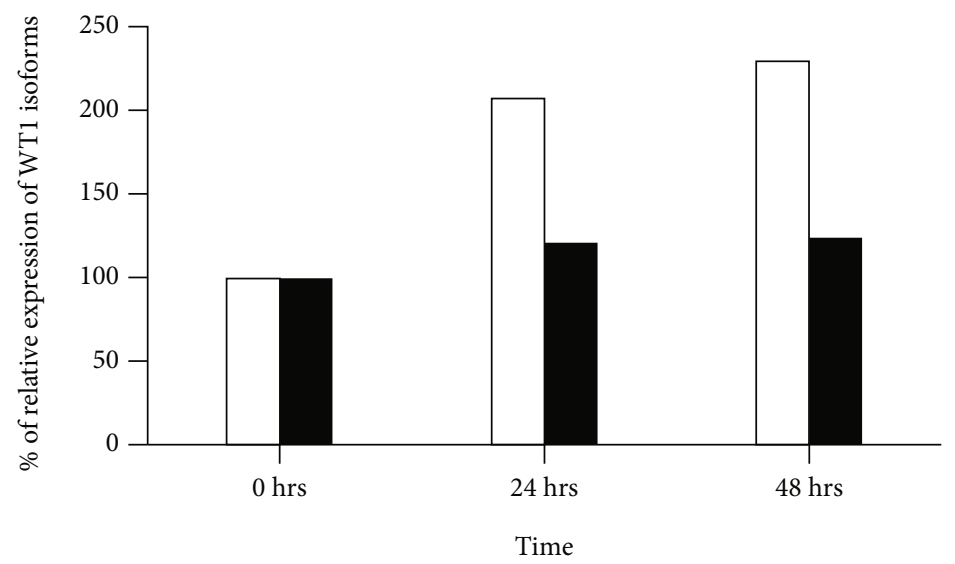

(c)

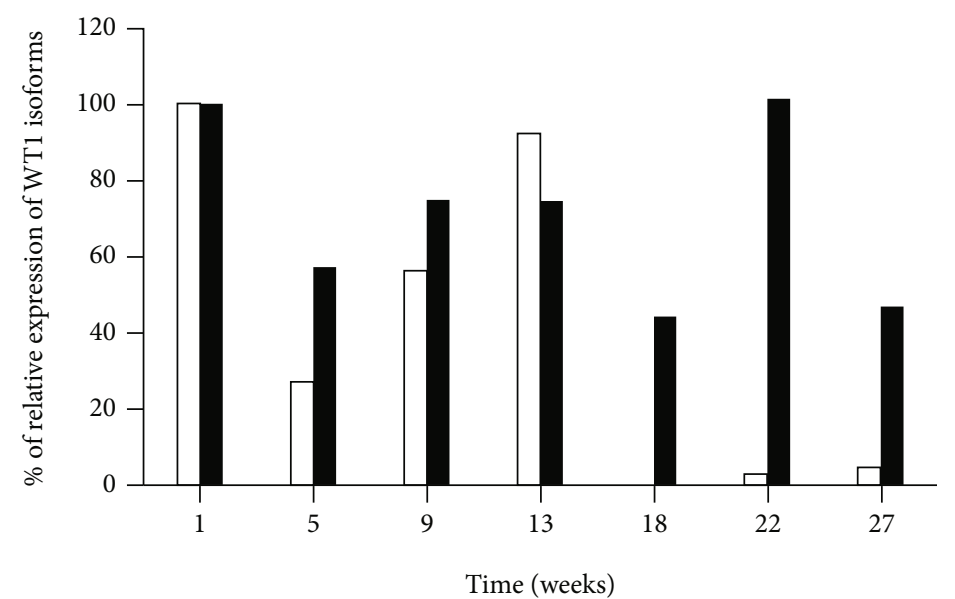

(d)

FIGURE 2: Expression of WT1 in MCF-7 cells cultured with estrogen depletion. (a) The 36-38 kDa and 52-54 kDa WT1 isoform expression in MCF-7 cells in depletion of estrogen in a short term (hours). (b) The $36-38 \mathrm{kDa}$ and $52-54 \mathrm{kDa}$ WT1 isoform expression in MCF-7 cells following the long-term depletion of estrogen (until 27 weeks). In both figures, $\beta$-actin expression was used as the endogenous control. (c, d) Show the densitometry analysis of the relative expression of WT1 isoforms. The 52-54 kDa isoform is shown in white columns and the $36-38 \mathrm{kDa}$ isoform in black columns.

involved in cell proliferation, apoptosis, and cancer development and protect cells against etoposide-induced apoptosis $[47,48]$. Ectopic overexpression of the 17AA $(+) / \mathrm{KTS}(+)$ and 17AA (+)/KTS (-) wt 1 isoforms in MCF-7 cells reduces proapoptotic BAK and caspase-7 proteins, as well as p53 mRNA levels [49]. Burwell et al. associated the specific presence of the 17AA (+)/KTS (-) wt 1 isoform with a reduction in cell proliferation and with the appearance of highly organized acinar cellular aggregates; the 17AA (+)/KTS (+) WT1 isoform induced epithelial-mesenchymal transition and the redistribution of E-cadherin [43]. Other work in vitro analyzed that the 17AA (-)/KTS (-) WT1 isoform modulates the expression of cytoskeletal regulatory proteins such as $\alpha$-actinin 1 , cofilin, and gelsolin, allowing cancer cells to acquire a more aggressive phenotype [50].

Other studies have associated the 17AA (+)/KTS (+) wt1 isoform with differentiation block, but cell proliferation is induced in 32D cl3 myeloid progenitor cells [51] and normal myeloid cells in response to granulocyte-CSF [52]. Tuna and Itamochi showed that the treatment of MCF-7 cells with insulin-like growth factor I (IGF-I) increases WT1 protein expression by $77 \%$, especially the $17 \mathrm{AA}(+) / \mathrm{KTS}(-)$ wt 1 isoform [16]. One of the possible hypotheses of the multiple activities of $w t 1$ isoforms may be due to protein-protein 


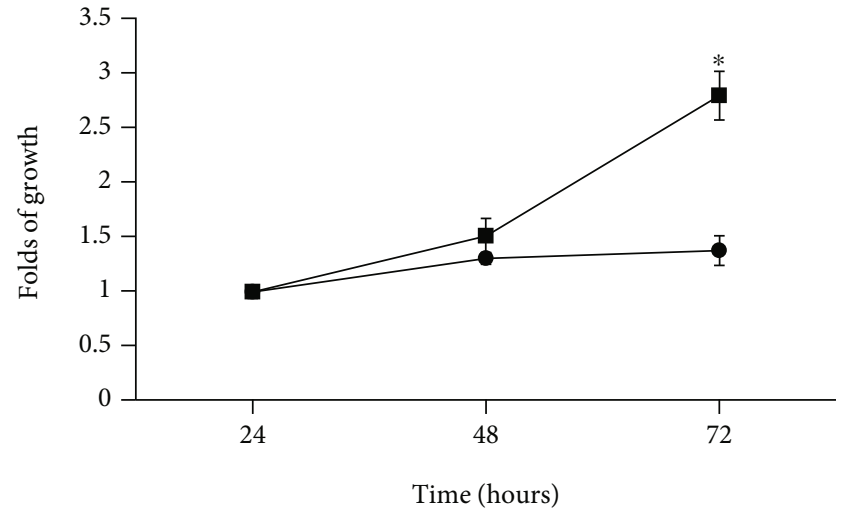

(a)

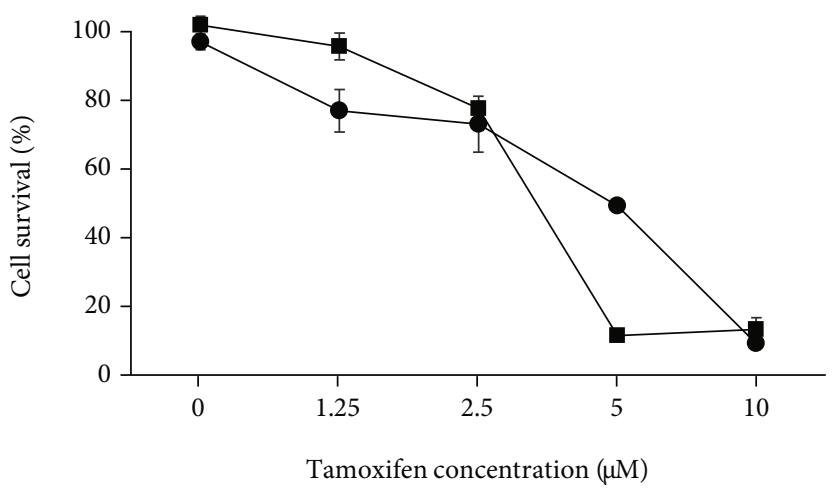

(b)

FIGURE 3: Growth kinetics and effect of tamoxifen on MCF-7 LTED cells. (a) The growth of MCF-7 cells during 27 weeks of estrogen depletion as compared to MCF-7 cells cultured under normal conditions. Cell counts were analyzed at 24 and 48 hours. Each assay was carried out in triplicate with the standard error shown. (b) The sensitivity to tamoxifen was tested using the following concentrations: $1.25 \mu \mathrm{M}, 2.5 \mu \mathrm{M}, 5 \mu \mathrm{M}$, and $10 \mu \mathrm{M}$ in MCF-7 LTED cells $(\mathbf{)})$ and MCF-7 cells under normal conditions ( $\mathbf{\square})$. All data are the mean \pm SD of three independent experiments $\left({ }^{*} p<0.05\right)$.

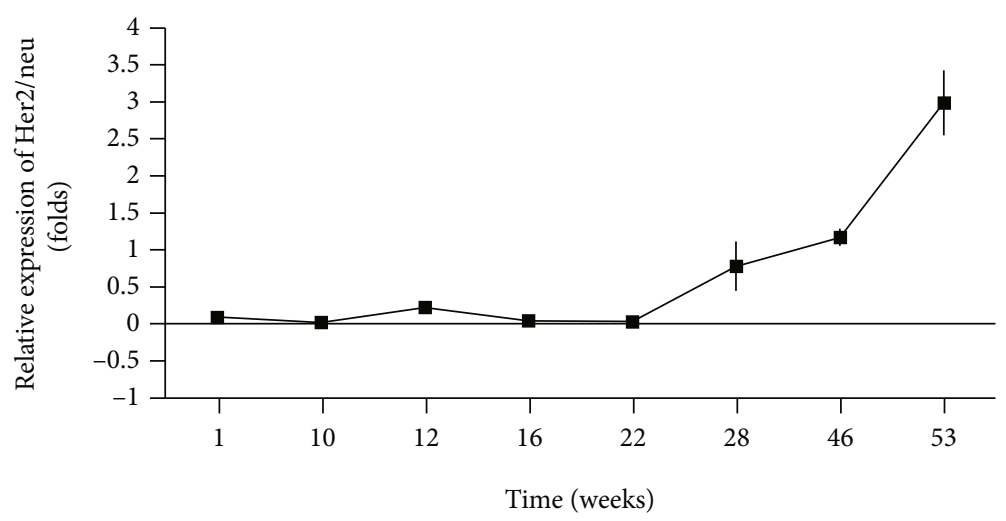

(a)

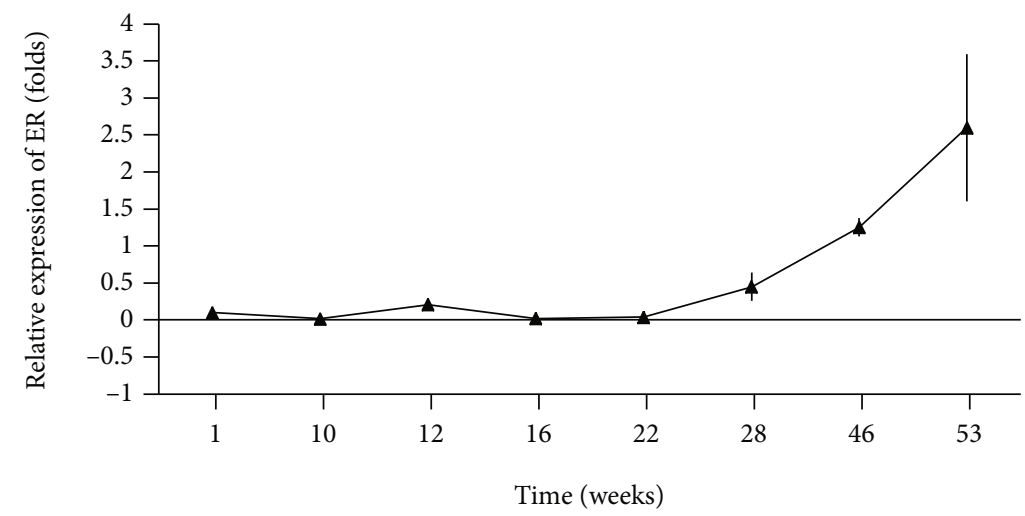

(b)

FIGURE 4: Expression of tumor markers Her2/neu and estrogen receptor (ER) in MCF-7 LTED cells by quantitative RT-PCR. The graph (a) shows the relative expression of Her2/neu $(\boldsymbol{\square})$, and graph (b) shows the relative expression of ER ( $\boldsymbol{\Delta})$. All the experiments were performed in triplicate with $\beta$-actin as the endogenous control.

interactions in the 17AA region. Several publications have described interactions of WT1 with proteins such as PAR4 and $\mathrm{p} 53$, so it should be considered in future studies which proteins interact with the various isoforms of WT1 [53-55].
We developed a model to cultivate MCF-7 cells under conditions of estrogen depletion, to mimic the process that occurs naturally with menopause, and the use of aromatase inhibitors as hormonal therapy in breast cancer. In the 
estrogen depletion trial, an increase in the expression of the $52-54 \mathrm{kDa}$ WT1 isoform was observed at 24 hours, and this expression was observed up to week 13; however, expression disappeared later. On the other hand, the expression of the $36-38 \mathrm{kDa}$ WT1 isoform was not affected in the short-term trial, but the expression was observed from the first week and was fairly constant until week 27 . We hypothesize that the increase in the expression of $36-38 \mathrm{kDa}$ WT1 isoform is involved in changes during estrogen depletion, which may be associated with the loss of the repression domain of WT1; this could offset the decrease in proliferation mediated by estrogens since the $36-38 \mathrm{kDa}$ WT1 isoform does not show transcriptional repression [19]. The proliferation of cells cultured with estrogen depletion showed a significant decrease, in addition to presenting a slight insensitivity to the antiproliferative activity of tamoxifen. ZapataBenavides et al. showed a dose-response effect on the expression of the $52-54 \mathrm{kDa}$ WT1 protein after the administration of $17 \beta$-estradiol to MCF-7 cells, but the $36-38 \mathrm{kDa}$ WT1 isoform in this work was not analyzed [32]. Artibani et al. in their results found an association between the expression of WT1 with ER-alpha [56]. Nasomyon et al. increased the specific expression of isoforms in MCF-7 cells, and all isoforms showed an increase in the expression of ER-alpha and Her2; however, the 17AA isoforms showed the greatest increases in ER-alpha and Her2 [46]. These results suggest that estrogen stimulation plays a role in modulating WT1 isoforms, thereby affecting cellular behavior.

We then analyzed the quantitative expression of ER and Her2/neu, and in both cases, a gradual increase was observed during MCF-7 estrogen depletion. This coincides with the results of Wang and Wang, who observed estrogen independence in MCF-7 cells through the mitogen-activated protein kinase (MAPK) pathway $[38,40]$. In a high passage model of MCF-7 cells (MCF-7H), the estrogen-independent and antiestrogen insensitive growth of MCF7H cells led to high levels of Her2/neu, EGFR, and ER- $\alpha$ in breast cancer cells [38], which would explain the increase in ER and Her2/ neu transcripts in cells in the context of estrogen depletion. In general, our results show changes in the expression of the different isoforms of WT1 during the adaptation process of MCF-7 cells to estrogen depletion, mainly involving the presence of the $36-38 \mathrm{kDa}$ WT1 isoform and loss of the expression of the $52-54 \mathrm{kDa}$ WT1 isoform. This behavior is related to the tumor status of the analyzed cell lines, as it was observed that only the ER-positive cell lines expressed the $52-54 \mathrm{kDa}$ WT1 isoform; this was absent in the ERnegative cell lines. There are currently few studies where the $36-38 \mathrm{kDa}$ WT1 isoform is analyzed, so it is important to carry out a characterization of the WT1 isoforms present in samples from breast cancer patients with variable tumor marker status. Finally, we conclude that changes in WT1 isoforms during estrogen depletion in MCF-7 cells may play a role in hormone-independent adaptation to tumor growth. With our results, it is very difficult to assign biological properties during this estrogen depletion model; however, it was evident how the isoforms described as truncated by some researchers $(36-38 \mathrm{kDa})$ may be implicit in the aggressiveness of the neoplasia. A recent work shows the transcrip- tional capacity of the KTS +/- isoforms of WT1, showing that the KTS + isoform has greater transcriptional activation than the KTS - isoform, suggesting the possibility that the insertion of the three amino acids does not inactivate or they reduce the transcriptional capacity, but it can expand their capacity to regulate other promoter regions.

\section{Data Availability}

All the data used to support the findings of this study are included within the article.

\section{Conflicts of Interest}

The authors declare that they have no conflicts of interest.

\section{Authors' Contributions}

Saavedra-Alonso Santiago, Zapata-Benavides Pablo, Mendoza-Gamboa Edgar, Chavez-Escamilla Ana Karina, Arellano-Rodríguez Mariela, and Rodriguez-Padilla Cristina contributed equally to this work.

\section{Acknowledgments}

This work was supported by the Immunology and Virology Department of the Faculty of Biological Sciences, Universidad Autónoma de Nuevo León (UANL), and the Support Program for Scientific and Technological Research PAICYT-UANL (SA602-18). Our acknowledgments extend to http://Proof-Reading-Service.com for linguistic review.

\section{References}

[1] R. Ambu, L. Vinci, C. Gerosa et al., "WT1 expression in the human fetus during development," European Journal of Histochemistry, vol. 59, no. 2, p. 2499, 2015.

[2] N. Tatsumi, N. Hojo, H. Sakamoto et al., "Identification of a novel C-terminal truncated WT1 isoform with antagonistic effects against major WT1 isoforms," PLoS One, vol. 10, no. 6, article e0130578, 2015.

[3] M. W. Mayo, C. Y. Wang, S. S. Drouin et al., "WT1 modulates apoptosis by transcriptionally upregulating the bcl-2 protooncogene," The EMBO Journal, vol. 18, no. 14, pp. 39904003, 1999.

[4] Y. Han, S. San-Marina, J. Liu, and M. D. Minden, “Transcriptional activation of c- _myc_ proto-oncogene by WT1 protein," Oncogene, vol. 23, no. 41, pp. 6933-6941, 2004.

[5] L. A. Simpson, E. A. Burwell, K. A. Thompson, S. Shahnaz, A. R. Chen, and D. M. Loeb, "The antiapoptotic gene A1/ BFL1 is a WT1 target gene that mediates granulocytic differentiation and resistance to chemotherapy," Blood, vol. 107, no. 12, pp. 4695-4702, 2006.

[6] G. McCarty, O. Awad, and D. M. Loeb, "WT1 protein directly regulates expression of vascular endothelial growth factor and is a mediator of tumor response to hypoxia," The Journal of Biological Chemistry, vol. 286, no. 51, pp. 43634-43643, 2011.

[7] H. Bansal, T. Seifert, C. Bachier et al., "The transcription factor Wilms tumor 1 confers resistance in myeloid leukemia cells against the proapoptotic therapeutic agent TRAIL (tumor necrosis factor $\alpha$-related apoptosis-inducing ligand) by 
regulating the antiapoptotic protein Bcl-xL," The Journal of Biological Chemistry, vol. 287, no. 39, pp. 32875-32880, 2012.

[8] C. Xu, C. Wu, Y. Xia et al., "WT1 promotes cell proliferation in non-small cell lung cancer cell lines through up-regulating cyclin D1 and p-pRb in vitro and in vivo," PLoS One, vol. 8, no. 8, article e68837, 2013.

[9] P. Moffett, W. Bruening, H. Nakagama et al., "Antagonism of WT1 activity by protein self-association," Proceedings of the National Academy of Sciences of the United States of America, vol. 92, no. 24, pp. 11105-11109, 1995.

[10] J. C. Reddy, J. C. Morris, J. Wang et al., "WT1-mediated transcriptional activation is inhibited by dominant negative mutant proteins," The Journal of Biological Chemistry, vol. 270, no. 18, pp. 10878-10884, 1995.

[11] D. Kennedy, T. Ramsdale, J. Mattick, and M. Little, “An RNA recognition motif in Wilms' tumour protein (WT1) revealed by structural modelling," Nature Genetics, vol. 12, no. 3, pp. 329-332, 1996.

[12] F. J. Rauscher, J. F. Morris, O. E. Tournay, D. M. Cook, and T. Curran, "Binding of the Wilms' tumor locus zinc finger protein to the EGR-1 consensus sequence," Science, vol. 250, no. 4985, pp. 1259-1262, 1990.

[13] N. Bardeesy and J. Pelletier, "Overlapping RNA and DNA binding domains of the wt1 tumor suppressor gene product," Nucleic Acids Research, vol. 26, no. 7, pp. 1784-1792, 1998.

[14] H. Nakagama, G. Heinrich, J. Pelletier, and D. E. Housman, "Sequence and structural requirements for high-affinity DNA binding by the WT1 gene product," Molecular and Cellular Biology, vol. 15, no. 3, pp. 1489-1498, 1995.

[15] C. Dechsukhum, J. L. Ware, A. Ferreira-Gonzalez, D. S. Wilkinson, and C. T. Garrett, "Detection of a novel truncated WT1 transcript in human neoplasia," Molecular Diagnosis, vol. 5, no. 2, pp. 117-128, 2000.

[16] M. Tuna and H. Itamochi, "Insulin-like growth factor I regulates the expression of isoforms of Wilms' tumor 1 gene in breast cancer," Tumori, vol. 99, no. 6, pp. 715-722, 2013.

[17] D. A. Haber, R. L. Sohn, A. J. Buckler, J. Pelletier, K. M. Call, and D. E. Housman, "Alternative splicing and genomic structure of the Wilms tumor gene WT1," Proceedings of the National Academy of Sciences of the United States of America, vol. 88, no. 21, pp. 9618-9622, 1991.

[18] W. Bruening and J. Pelletier, "A non-AUG translational initiation event generates novel WT1 isoforms," The Journal of Biological Chemistry, vol. 271, no. 15, pp. 8646-8654, 1996.

[19] V. Scharnhorst, P. Dekker, A. J. van der Eb, and A. G. Jochemsen, "Internal translation initiation generates novel WT1 protein isoforms with distinct biological properties," The Journal of Biological Chemistry, vol. 274, no. 33, pp. 23456-23462, 1999.

[20] A. R. Dallosso, A. L. Hancock, K. W. Brown, A. C. Williams, S. Jackson, and K. Malik, "Genomic imprinting at the WT1 gene involves a novel coding transcript (AWT1) that shows deregulation in Wilms' tumours," Human Molecular Genetics, vol. 13, no. 4, pp. 405-415, 2004.

[21] A. Hossain, M. Nixon, M. T. Kuo, and G. F. Saunders, "N-terminally truncated WT1 protein with oncogenic properties overexpressed in leukemia," The Journal of Biological Chemistry, vol. 281, no. 38, pp. 28122-28130, 2006.

[22] Y. Oji, S. Miyoshi, H. Maeda et al., "Overexpression of the Wilms' tumor gene WT1 in de novo lung cancers," International Journal of Cancer, vol. 100, no. 3, pp. 297-303, 2002.
[23] Y. Oji, H. Yamamoto, M. Nomura et al., "Overexpression of the Wilms' tumor gene WT1 in colorectal adenocarcinoma," Cancer Science, vol. 94, no. 8, pp. 712-717, 2003.

[24] Y. Oji, S. Nakamori, M. Fujikawa et al., "Overexpression of the Wilms' tumor gene WT1 in pancreatic ductal adenocarcinoma," Cancer Science, vol. 95, no. 7, pp. 583-587, 2004.

[25] D. M. Loeb, E. Evron, C. B. Patel et al., "Wilms' tumor suppressor gene (WT1) is expressed in primary breast tumors despite tumor-specific promoter methylation," Cancer Research, vol. 61, no. 3, pp. 921-925, 2001.

[26] Y. Oji, H. Ogawa, H. Tamaki et al., "Expression of the Wilms' tumor gene WT1 in solid tumors and its involvement in tumor cell growth," Japanese Journal of Cancer Research, vol. 90, no. 2, pp. 194-204, 1999.

[27] T. Yamauchi, E. Negoro, S. Lee et al., "Detectable Wilms' tumor-1 transcription at treatment completion is associated with poor prognosis of acute myeloid leukemia: a single institution's experience," Anticancer Research, vol. 33, no. 8, pp. 3335-3340, 2013.

[28] E. Drakos, G. Z. Rassidakis, P. Tsioli, R. Lai, D. Jones, and L. J. Medeiros, "Differential expression of WT1 gene product in non-Hodgkin lymphomas," Applied Immunohistochemistry \& Molecular Morphology, vol. 13, no. 2, pp. 132-137, 2005.

[29] G. B. Silberstein, K. Van Horn, P. Strickland, C. T. Roberts Jr., and C. W. Daniel, "Altered expression of the WT1 wilms tumor suppressor gene in human breast cancer," Proceedings of the National Academy of Sciences of the United States of America, vol. 94, no. 15, pp. 8132-8137, 1997.

[30] Y. Miyoshi, A. Ando, C. Egawa et al., "High expression of Wilms' tumor suppressor gene predicts poor prognosis in breast cancer patients," Clinical Cancer Research, vol. 8, no. 5, pp. 1167-1171, 2002.

[31] Y. Oji, Y. Miyoshi, E. Kiyotoh et al., "Absence of mutations in the Wilms' tumor gene WT1 in primary breast cancer," Japanese Journal of Clinical Oncology, vol. 34, no. 2, pp. 74-77, 2004.

[32] P. Zapata-Benavides, M. Tuna, G. Lopez-Berestein, and A. M. Tari, "Downregulation of Wilms' tumor 1 protein inhibits breast cancer proliferation," Biochemical and Biophysical Research Communications, vol. 295, no. 4, pp. 784-790, 2002.

[33] M. Tuna, A. Chavez-Reyes, and A. M. Tari, "HER2/_neu_ increases the expression of Wilms' tumor 1 (WT1) protein to stimulate S-phase proliferation and inhibit apoptosis in breast cancer cells," Oncogene, vol. 24, no. 9, pp. 1648-1652, 2005.

[34] K. J. Livak and T. D. Schmittgen, "Analysis of relative gene expression data using real-time quantitative PCR and the $2^{-\Delta \Delta}{ }_{-} C_{-}$Tethod," Methods, vol. 25 , no. 4, pp. 402-408, 2001.

[35] M. Ghoncheh, Z. Pournamdar, and H. Salehiniya, "Incidence and mortality and epidemiology of breast cancer in the world," Asian Pacific Journal of Cancer Prevention, vol. 17, no. sup3, pp. 43-46, 2016.

[36] X. Dai, T. Li, Z. Bai et al., "Breast cancer intrinsic subtype classification, clinical use and future trends," American Journal of Cancer Research, vol. 5, no. 10, pp. 2929-2943, 2015.

[37] H. G. Russnes, O. C. Lingjærde, A. L. Børresen-Dale, and C. Caldas, "Breast cancer molecular stratification: from intrinsic subtypes to integrative clusters," The American Journal of Pathology, vol. 187, no. 10, pp. 2152-2162, 2017.

[38] L. Wang and Z. Y. Wang, "The Wilms' tumor suppressor WT1 induces estrogen-independent growth and anti-estrogen 
insensitivity in ER-positive breast cancer MCF7 cells," Oncology Reports, vol. 23, no. 4, pp. 1109-1117, 2010.

[39] I. R. Hutcheson, J. M. Knowlden, T. A. Madden, D. Barrow, J. M. Gee, and A. E. Wakeling, "Oestrogen receptor-mediated modulation of the EGFR/MAPK pathway in tamoxifenresistant MCF-7 cells," Breast Cancer Research and Treatment, vol. 81, no. 1, pp. 81-93, 2003.

[40] L. Yang, Y. Han, F. Suarez Saiz, and M. D. Minden, "A tumor suppressor and oncogene: the WT1 story," Leukemia, vol. 21, no. 5, pp. 868-876, 2007.

[41] Y. Oji, H. Inohara, M. Nakazawa et al., "Overexpression of the Wilms' tumor gene WT1 in head and neck squamous cell carcinoma," Cancer Science, vol. 94, no. 6, pp. 523-529, 2003.

[42] T. Ueda, Y. Oji, N. Naka et al., "Overexpression of the Wilms' tumor gene WT1 in human bone and soft-tissue sarcomas," Cancer Science, vol. 94, no. 3, pp. 271-276, 2003.

[43] E. A. Burwell, G. P. McCarty, L. A. Simpson, K. A. Thompson, and D. M. Loeb, "Isoforms of Wilms' tumor suppressor gene (WT1) have distinct effects on mammary epithelial cells," Oncogene, vol. 26, no. 23, pp. 3423-3430, 2007.

[44] J. M. Siehl, M. Reinwald, K. Heufelder, H. D. Menssen, U. Keilholz, and E. Thiel, "Expression of Wilms' tumor gene 1 at different stages of acute myeloid leukemia and analysis of its major splice variants," Annals of Hematology, vol. 83, no. 12 , pp. 745-750, 2004.

[45] R. Gillmore, S. A. Xue, A. Holler et al., "Detection of Wilms' tumor antigen-specific CTL in tumor-draining lymph nodes of patients with early breast cancer," Clinical Cancer Research, vol. 12, no. 1, pp. 34-42, 2006.

[46] T. Nasomyon, S. Samphao, S. Sangkhathat, S. Mahattanobon, and P. Graidist, "Correlation of Wilms' tumor 1 isoforms with HER2 and ER- $\alpha$ and its oncogenic role in breast cancer," Anticancer Research, vol. 34, no. 3, pp. 1333-1342, 2014.

[47] K. Ito, Y. Oji, N. Tatsumi et al., "Antiapoptotic function of 17AA(+)WT1 (Wilms' tumor gene) isoforms on the intrinsic apoptosis pathway," Oncogene, vol. 25, no. 30, pp. 42174229, 2006.

[48] N. Tatsumi, Y. Oji, N. Tsuji et al., "Wilms' tumor gene WT1shRNA as a potent apoptosis-inducing agent for solid tumors," International Journal of Oncology, vol. 32, no. 3, pp. 701-711, 2008.

[49] P. Graidist, R. Nawakhanitworakul, J. Saekoo, C. Dechsukhum, and K. Fujise, "Anti-apoptotic function of T-KTS+, T-KTS-, WT1+/+ and WT1+/- isoforms in breast cancer," Asian Biomedicine, vol. 4, no. 5, pp. 711-720, 2010.

[50] T. Jomgeow, Y. Oji, N. Tsuji et al., "Wilms' tumor gene WT1 $17 \mathrm{AA}(-) / \mathrm{KTS}(-)$ isoform induces morphological changes and promotes cell migration and invasion in vitro," Cancer Science, vol. 97, no. 4, pp. 259-270, 2006.

[51] K. Inoue, H. Tamaki, H. Ogawa et al., "Wilms' tumor gene (WT1) competes with differentiation-inducing signal in hematopoietic progenitor cells," Blood, vol. 91, no. 8, pp. 2969-2976, 1998.

[52] A. Tsuboi, Y. Oka, H. Ogawa et al., "Constitutive expression of the Wilms' tumor gene WT1 inhibits the differentiation of myeloid progenitor cells but promotes their proliferation in response to granulocyte-colony stimulating factor (G-CSF)," Leukemia Research, vol. 23, no. 5, pp. 499-505, 1999.

[53] S. K. Cheema, S. K. Mishra, V. M. Rangnekar, A. M. Tari, R. Kumar, and G. Lopez-Berestein, "Par-4 transcriptionally regulates Bcl-2 through a WT1-binding site on the _bcl-2_ promoter," The Journal of Biological Chemistry, vol. 278, no. 22, pp. 19995-20005, 2003.

[54] S. Maheswaran, S. Park, A. Bernard et al., "Physical and functional interaction between WT1 and p53 proteins," Proceedings of the National Academy of Sciences of the United States of America, vol. 90, no. 11, pp. 5100-5104, 1993.

[55] D. J. Richard, V. Schumacher, B. Royer-Pokora, and S. G. Roberts, "Par4 is a coactivator for a splice isoform-specific transcriptional activation domain in WT1," Genes \& Development, vol. 15, no. 3, pp. 328-339, 2001.

[56] M. Artibani, A. H. Sims, J. Slight et al., “_WT1_expression in breast cancer disrupts the epithelial/mesenchymal balance of tumour cells and correlates with the metabolic response to docetaxel," Scientific Reports, vol. 7, no. 1, 2017. 